Rapp. Grønlands geol. Unders. 58, 43-47 (1973)

\title{
PRELIMINARY OBSERVATIONS ON THE PALAEOMAGNETISM AND RADIOMETRIC AGES OF THE TERTIARY BASALT SEQUENCE OF SCORESBY SUND, EAST GREENLAND
}

\author{
E. A. Hailwood, D. H. Tarling, J. G. Mitchell and R. Løvlie
}

\section{Introduction}

During the 1972 summer field season a detailed sampling programme was undertaken on the Tertiary basalt sequence on the south side of Scoresby Sund, East Greenland, with the view to obtaining a systematic collection of orientated samples for palaeomagnetic work. Additional samples were collected from key localities for radiometric age determinations. A previous palaeomagnetic pilot-study of a limited number of samples from the Tertiary lavas of this region by Tarling (1967), indicated the presence of a moderately stable remanent magnetisation, which was reversed with respect to the Earth's present magnetic field. The present work has been undertaken in the hope that a detailed study of the remanent magnetisation of the whole sequence might reveal changes in polarity which could be used for correlation purposes. The establishment of a polarity reversal sequence in these lavas has been attempted previously by Watt \& Watt (1971), on the basis of the direct measurement of magnetic polarity in the field, using a hand compass. In order to check the reliability of such field polarity determinations, a portable fluxgate magnetometer was used to make slightly more accurate direct measurements, which could subsequently be compared with the much more precise results obtained from laboratory measurement of the carefully orientated samples.

A second important aim of the palaeomagnetic and radiometric studies is to attempt to obtain information relevant to the history of evolution of the extreme Norh Atlantic Ocean basin.

This report describes preliminary palaeomagnetic results from a portion of the basalt sequence sampled at the north-east side of the glacier Sydbræ and also some preliminary radiometric age determinations from this, and other sections of the basalt series.

\section{Sampling and field polarity measurements}

A total thickness of some 2800 metres of the basalt sequence was sampled at a 
series of sections, based on four camps at progressively higher altitudes, ranging from the lowest flows, outcropping immediately above the migmatitic basement on the south coast of Gåsefjord, to the highest exposed flows, outcropping at the edge of the ice-cap at Skrænterne. The sampling programme was based on the detailed mapping of the basalts by Stuart \& Margrethe Watt, whose help and advice is gratefully acknowledged. Sampling was performed by means of a portable coring drill, which provided cores approximately 1 inch in diameter, and up to 8 inches in length. These were orientated relative to the vertical by a clinometer, and relative to true north by sun-compass or magnetic compass, or both.

In general at least three separately orientated cores were collected at each site. Wherever possible one site was located near the base of the lower (colonnade) part of the flow, and a second site within the upper (entablature) part (Watt \& Watt, 1971). In the case of thick flows (greater than about 50 metres) an extra site was usually sampled near the top of the colonnade part. 'Flow-groups', comprising a sequence of many (often five to ten or more) thin, apparently closely related flows, were occasionally observed, and these groups were usually treated as single flows, and sampled at two to three sites only. Occasional extra sites were situated within 'baked-contact' zones, or other regions of particular interest.

Field polarity measurements were made by detaching small samples from the outcrop with a hammer and chisel, and measuring the approximate direction of magnetisation relative to the upper surface, by means of the portable fluxgate magnetometer. Upward-directed magnetisations were classified as 'reversed', and downward-directed magnetisations as 'normal'.

\section{Palaeomagnetic measurements}

Specimens, approximately one inch in length, have been sliced from each of the one inch diameter drill cores, and the direction and intensity of natural remanent magnetisation (NRM) of these specimens measured on a P. A. R. spinner magnetometer. These directions are plotted as a function of height above sea-level in fig. 6 . The inclination of the NRM is specified in degrees above (negative) or below (positive) the horizontal, and the declination in degrees clockwise from true north. There was frequently a considerable scatter in the directions of magnetisation of different samples from the same site. Because of this high scatter each of the individual sample directions have been plotted separately, and no attempt has been made to calculate site-mean directions. The portion of the sequence between 540 and 640 metres was occupied by a broad scree-covered bench, so that no samples could be obtained from this range. A further 63 samples were collected from various points within the total height range shown in fig. 6 , but measurements had not been completed on these samples at the time of writing. However it is not felt 


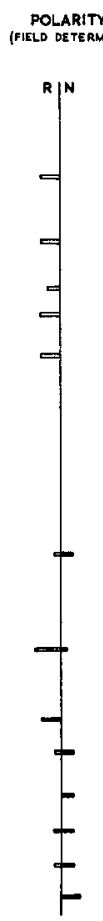

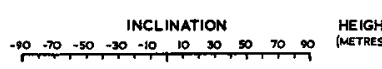
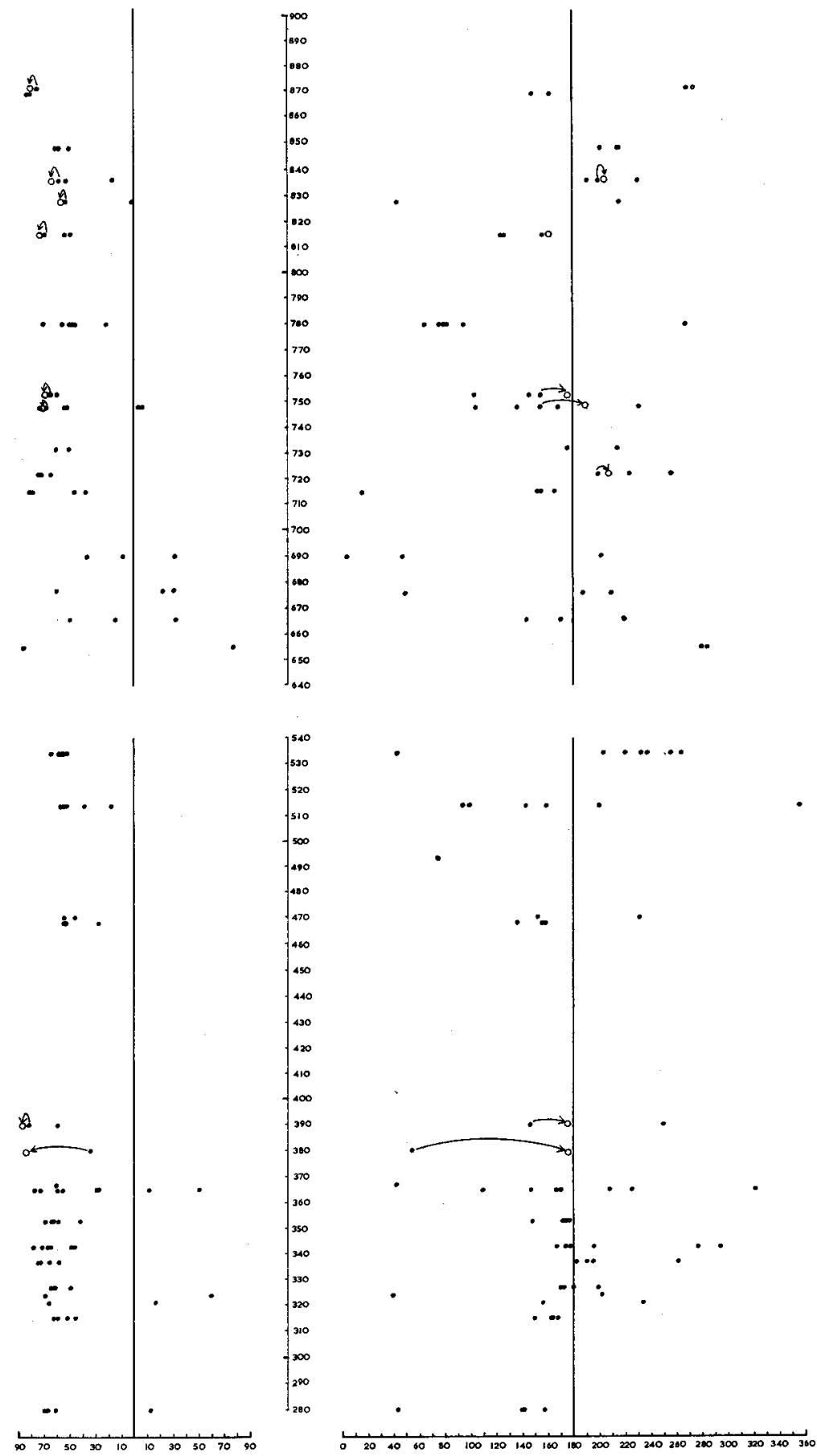

Fig. 6. Diagram showing magnetic polarity, inclination and declination of samples from a composite profile through part of the basalt sequence. 
that the future inclusion of data from these samples will radically alter interpretations based on the existing data.

The polarity observations made in the field with the portable fluxgate magnetometer are plotted in the left-hand column of fig. 6. Solid bars represent 'normal' polarities, and open bars 'reversed' polarities. The lengths of the bars are proportional to the number of samples measured (minimum 1 sample, maximum 4 samples of either polarity).

\section{Discussion}

True polarity reversals of the Earth's magnetic field are represented by a change in inclination from a negative value to a positive value of similar magnitude (or vice-versa), and by a $180^{\circ}$ change in declination. Although there is a considerable scatter in the NRM inclinations shown in fig. 6 , an overall mean of approximately $-60^{\circ}$ is evident. Some ten percent of the total number of samples so far measured have yielded positive inclinations, but in only two samples do these have values of about $+60^{\circ}$. Furthermore, at sites at which positive values occur, there are usually at least an equal number of samples with negative inclinations. The value of the declination is much more variable than that of the inclination, but the overall mean value is in the region of $180^{\circ}$. Nowhere in the sequence plotted in fig. 6 is there an obvious and consistent change in value of about $180^{\circ}$, that might represent a true reversal.

Partial demagnetisation stability tests have so far been applied to nine pilot specimens, selected at random from this sequence. Six of these specimens have inclinations in the range -55 to -75 degrees, and declinations in the range 150 to 210 degrees. These samples show a very high degree of stability, undergoing changes in direction of only a few degrees during partial demagnetisation in alternating fields of up to 350 oersteds (peak). The remaining three samples show a lower degree of stability, and apparently carry a less-stable component, probably acquired in the present Earth's field. Removal of this component in fields of between 50 and 150 oersteds results in the isolation of a stable component with an inclination of between -65 and -80 degrees, and a declination of about $180^{\circ}$. The directions of magnetisation of the pilot-samples after partial demagnetisation at these fields are plotted as open circles in fig. 6 and joined to their corresponding NRM directions by an arrow, where measurable changes occur.

Although no stability tests have yet been applied to the samples with positive inclinations, it seems highly likely that these samples also carry a secondary component, acquired in the present Earth's field, and of higher magnitude than in the samples so far demagnetised.

In view of the above remarks, it is apparent that the portion of the basalt sequence represented in fig. 6 contains no true changes in polarity, but that the 
Earth's field remained reversed during the whole period of extrusion of these basalts. The field polarity-measurements made with the fluxgate magnetometer indicated 31 'normal' samples out of a total of 106 in this section, and these determinations clearly have no significance so far as true reversals of the Earth's field are concerned. Pending detailed measurements on the rest of the sequence, caution must be exercised, therefore, in the interpretation of 'polarity changes' detected in the field by either hand-compass or fluxgate magnetometer, unless these are consistent over large thicknesses of lava.

It is also apparent that many of the samples carry a remanent magnetisation with a high degree of stability, and that detailed measurements and partial demagnetisation experiments are likely to yield meaningful palaeomagnetic pole-positions which will aid in the interpretation of the history of movement of Greenland away from north-west Europe.

\section{Radiometric ages}

Preliminary K/Ar age determinations have been carried out on samples from a total of seven sites distributed throughout the basalt sequence. The material selected for these determinations was particularly fresh, and repeatability of results is good. The ages obtained lie in the range 47 to $52 \mathrm{~m}$. y. and are significantly younger than those of the north-west Scotland lavas. The full significance of these results will be discussed in a future report, when more detailed measurements are complete.

\section{References}

Watt, W. S. \& Watt, M. 1971: Preliminary report of the mapping of the basalts of parts of Milne Land and Gåseland. Rapp. Grønlands geol. Unders. 37, 42-50.

Tarling, D. H. 1967: The palaeomagnetic properties of some Tertiary lavas from East Greenland. Earth planet. Sci. Lett. 3, 81-88. 